\title{
Colonoscopy Surveillance After Colorectal Cancer
}

Citation for published version (APA):

Ramphal, W., Boeding, J. R. E., Schreinemakers, J. M. J., Gobardhan, P. D., Rutten, H. J. T., \& Crolla, R. M. P. H. (2020). Colonoscopy Surveillance After Colorectal Cancer: the Optimal Interval for Follow-Up. Journal of Gastrointestinal Cancer, 51(2), 469-477. https://doi.org/10.1007/s12029-019-00254-5

Document status and date:

Published: 01/06/2020

DOI:

10.1007/s12029-019-00254-5

Document Version:

Publisher's PDF, also known as Version of record

Document license:

Taverne

Please check the document version of this publication:

- A submitted manuscript is the version of the article upon submission and before peer-review. There can be important differences between the submitted version and the official published version of record.

People interested in the research are advised to contact the author for the final version of the publication, or visit the DOI to the publisher's website.

- The final author version and the galley proof are versions of the publication after peer review.

- The final published version features the final layout of the paper including the volume, issue and page numbers.

Link to publication

\footnotetext{
General rights Owners
rights.

- You may freely distribute the URL identifying the publication in the public portal. please follow below link for the End User Agreement:

www.umlib.nl/taverne-license

Take down policy

If you believe that this document breaches copyright please contact us at:

repository@maastrichtuniversity.nl

providing details and we will investigate your claim.
}

Copyright and moral rights for the publications made accessible in the public portal are retained by the authors and/or other copyright owners and it is a condition of accessing publications that users recognise and abide by the legal requirements associated with these

- Users may download and print one copy of any publication from the public portal for the purpose of private study or research.

- You may not further distribute the material or use it for any profit-making activity or commercial gain

If the publication is distributed under the terms of Article $25 \mathrm{fa}$ of the Dutch Copyright Act, indicated by the "Taverne" license above, 


\title{
Colonoscopy Surveillance After Colorectal Cancer: the Optimal Interval for Follow-Up
}

\author{
Winesh Ramphal ${ }^{1}$ (1) - Jeske R. E. Boeding ${ }^{1}$ - Jennifer M. J. Schreinemakers ${ }^{1}$ • Paul D. Gobardhan ${ }^{1}$. \\ Harm J. T. Rutten ${ }^{2,3} \cdot$ Rogier M. P. H. Crolla ${ }^{1}$
}

Published online: 3 June 2019

(C) Springer Science+Business Media, LLC, part of Springer Nature 2019

\begin{abstract}
Purpose Patients who have undergone curative surgery for colorectal cancer are at risk of developing a metachronous colorectal tumour or anastomotic recurrence. The aim of this study was to determine the incidence of recurrent colorectal cancer in a cohort of patients who participated in a colonoscopy surveillance programme.

Methods This single-centre retrospective observational cohort study included patients who underwent curative surgery for colorectal cancer between 2005 and 2015. All reports of postoperative colonoscopies were retrieved to calculate the incidence rates of recurrence and metachronous colorectal cancer.

Results Of 2420 patients, 1644 (67.9\%) underwent at least one postoperative colonoscopy and 776 (32.1\%) did not. In 1087 patients, colonoscopy was performed in the first 18 months after surgery, which detected $34(3.1 \%)$ instances of metachronous colorectal tumours or anastomotic recurrence. Thirty-three additional patients were also diagnosed with recurrent colorectal cancer, but the tumours were detected by other diagnostic modalities or detected perioperatively, rather than by colonoscopy. Conclusions Patients with a history of colorectal cancer have an increased risk for a second colorectal tumour. Therefore, we recommend a colonoscopic surveillance programme with the first colonoscopy performed 1 year after curative surgery, which is in accordance with national guidelines.
\end{abstract}

Keywords Surveillance $\cdot$ Colonoscopy $\cdot$ Colorectal cancer $\cdot$ Follow-up

\section{Introduction}

Patients who have undergone a colorectal resection because of malignancy have a higher risk of developing a metachronous colorectal tumour. These tumours can involve either a second primary colorectal cancer (CRC) or anastomotic recurrence. In the current literature, the reported incidence rates of metachronous CRC after previous curative resection are between 0.6 and $9 \%[1,2]$. The risk of second primary tumour is approximately $2.5 \%$ within the first 5 years [3]. There are

Winesh Ramphal

wramphal@amphia.nl; w.ramphal@gmail.com

1 Department of Surgery, Amphia Hospital Breda, Molengracht 21, 4818 CK Breda, The Netherlands

2 Department of Surgery, Catharina Hospital, Eindhoven, The Netherlands

3 GROW: School of Oncology and Developmental Biology, University of Maastricht, Maastricht, The Netherlands studies that show increasing incidence of metachronous tumours with time in general population and in patients with specified genetic predisposition [4, 5]. However, other studies show that the risk of developing metachronous $\mathrm{CRC}$ is highest within the first 2 to 3 years after diagnosis [6-8]. Mulder et al. found a cumulative incidence rate of metachronous CRC of $1.1 \%$ after 3 years. This is 1.4 times the incidence rate of CRC in the Netherlands [2]. Therefore, Dutch guidelines were adapted in 2014 to advise that the first colonoscopy surveillance should occur approximately 1 year after curative resection rather than at 2 to 3 years. However, this is a recommendation based on weak evidence [8]. This recommendation complies with international guidelines, which clearly state that a follow-up colonoscopy is indicated after surgery for CRC [9-12]. However, the guidelines differ regarding the time interval for monitoring the colon and rectum both for the first postoperative colonoscopy and for subsequent colonoscopies. Furthermore, some studies suggest that early endoscopy does not contribute to the detection of recurrence or metachronous tumours [13-15]. The intervals for prearranged follow-up colonoscopies vary among 
different clinics and institutions, with both overuse and underuse being reported after resection for CRC [16, 17]. In general, patients who have undergone surgical resection for stage I-III and/or intentional curable stage IV CRC are potential patients for surveillance colonoscopy. Patients with stage IV CRC that is unresectable for cure are generally not candidates for surveillance, because of the poor survival benefit. Preoperative colonoscopy can be incomplete due to tumour obstruction or be absent in some patients. These patients mostly present with an acute bowel obstruction requiring emergency surgical intervention. According to Dutch guidelines, such patients must undergo a completing colonoscopy within 3 months after resection to detect synchronous neoplasia [8].

To date, no study has analysed the ability of 1 -year postoperative surveillance colonoscopy to detect metachronous colorectal tumours or anastomotic recurrences. Since 2005 but before the implementation of routine colonoscopies as per the 2014 guidelines, we had performed the first followup colonoscopy 1 year after colorectal resection in the majority of our patients. The main aim of this study is to present the results of 11 years of endoscopic follow-up after surgery for CRC. In addition, based on our findings, we provide a recommendation regarding the optimal interval for first colonoscopy surveillance after curative resection.

\section{Methods}

\section{Data and Definitions}

At Amphia Hospital, patients diagnosed with CRC and treated with curative surgery were offered colonoscopy to detect recurrent disease. Patients who were diagnosed and treated between January 2005 and December 2015 were retrospectively reviewed. Our surgical team prospectively collected data on all CRC patients undergoing colorectal surgery because of a malignancy between 2005 and 2010. From 2011 onwards, trained personnel of the National Cancer Registration Centre (Integraal Kanker Centrum Nederland, IKNL) entered the data of CRC patients into the National Dutch Colorectal Audit database (DCRA). Data consisted of patient characteristics, preoperative imaging diagnostics, location of the tumour within the colon and/or rectum and whether or not a complete preoperative colonoscopy was performed. Data regarding surgery included curative surgical treatment. The results regarding postoperative colonoscopies as a part of the surveillance programme, completion colonoscopies, or other imaging techniques that were used to detect colorectal recurrence were retrospectively retrieved from medical charts. Major complications after colonoscopy requiring surgery or postponing colonoscopy were also ascertained. Colonoscopies were deemed complete if the bottom of caecum, ileocaecal valve, or terminal ileum was visualized and reported. Anastomotic recurrence was defined as tumour growth in the previous anastomotic suture line, irrespective of synchronous metastatic or other local recurrence [18]. Local recurrence was defined as tumour growth outside or inside the colonic/rectal wall, which can extend through this wall with perforation and/or invasion of adjacent organs or structures [19]. Metachronous tumours or second primary tumours were defined as luminal tumours located elsewhere in the colon or rectum at least 6 months after curative surgery for the primary tumour. Preoperative colonoscopy had to be complete in these patients for them to classify a new luminal tumour as metachronous. During follow-up interval, most of the patients were seen by the surgeon every 3 months during the first year and every 6 months thereafter. In the Netherlands, each follow-up visit includes a physical examination, measurement of the serum carcinoembryonic antigen (CEA), ultrasound of the abdomen and chest Xray. Chest $\mathrm{CT}$, abdominopelvic $\mathrm{CT}$, or positron emission tomography (PET) was performed when there was high suspicion of recurrence of disease on routine imaging studies. Recurrence of disease did not include distant metastases to other organs.

\section{Inclusion and Exclusion Criteria}

Patients were included if they had undergone surgery for their index CRC between 2005 and 2015. Patients were excluded if they had a previous history of CRC, an appendix carcinoma or pseudomyxoma peritonei (PMP). Patients were also excluded if they had undergone surgery for palliative purposes (palliative resection or debulking, palliative bypass, or palliative colostomy/ileostomy due to of obstructing symptoms). Amphia Hospital is a referral centre for (colorectal) liver metastases. Patients who were referred to Amphia Hospital by another hospital because of liver metastasis were also excluded.

\section{Ethical Approval}

For ethical approval, we consulted the national institutional review board's Medical research Ethics Committees United (MEC-U). Referring to this study (reference number W17.073), confirmation was received that the Medical Research Involving Human Subject Act (WMO) does not apply; therefore, official approval of this study by the MEC-U was not required under the WMO. We also consulted the institutional review board of Amphia Hospital (AMOA), and they confirmed that no formal written waiver of ethics approval was required, because of the retrospective design of the study. 


\section{Statistical Analysis}

The Kolmogorov-Smirnov test was used to determine whether the variables were normally distributed. Data are presented as the means and SD for normally distributed data and as medians and interquartile ranges (IQR) for non-normally distributed data. Differences in continuous variables between and among groups were tested using independent $t$ tests and oneway ANOVA, respectively. A two-sided $P$ value of less than 0.05 indicated statistical significance. All of the data analyses were performed with IBM SPSS software, version 24.

\section{Results}

Between 2005 and 2015, 2750 patients underwent surgery for CRC. In this patient group, 330 patients $(12.0 \%)$ were excluded because of non-curative treatment (Table 1). The remaining 2420 patients $(88.0 \%)$ were eligible for analysis (Fig. 1). A total of 1340 patients were male.

Preoperative colonoscopies were complete in 1332 patients (55.0\%). In 279 (11.6\%) patients, no preoperative colonoscopy had been performed. In the remaining 809 (33.4\%) patients, colonoscopy was incomplete mostly due to tumour obstruction. The rectum was the most common tumour location, followed by the sigmoid and caecum. Several types of resections were performed as outlined in Table 2. Among these resections, right hemicolectomy was performed most frequently, followed by low anterior resection and (recto) sigmoidal resection. Among the 2420 patients who had undergone surgery for CRC, eight patients had hereditary nonpolyposis colorectal cancer syndrome (HNPCC), and ten patients had IBD (seven patients with ulcerative colitis and three patients with Crohn's disease).

Of the 2420 patients who had undergone curative surgery, $1644(67.9 \%)$ had at least one colonoscopy during follow-up. A flowchart is provided in Fig. 1. The remaining 776 (32.1\%) patients did not undergo surveillance colonoscopy. The median age was statistical significant lower in het colonoscopy

Table 1 Number of excluded patients presented as N (\%)

\begin{tabular}{ll}
\hline Exclusion criteria & Excluded patients, $N=330\left(\%{ }^{*}\right)$ \\
\hline Palliative colostomy/ileostomy & $125(37.9 \%)$ \\
Palliative resection/debulking & $57(17.3 \%)$ \\
Referred liver patient & $42(12.7 \%)$ \\
History of colorectal cancer & $41(12.4 \%)$ \\
Palliative bypass & $33(10.0 \%)$ \\
Appendix carcinoma/PMP & $17(5.2 \%)$ \\
No surgical intervention & $11(3.3 \%)$ \\
Liver first & $4(1.2 \%)$ \\
\hline
\end{tabular}

*Percentage of patients who were excluded group (67 years (IQR 60-74) vs. 76 years (IQR 68-82), $P<0.0001)$. The main reasons for not participating in the colonoscopy surveillance programme were patient related factors, such as advanced age, co-morbidity and patient preference. Follow-up colonoscopy was not performed in patients after a total colectomy with a permanent ileostomy or in patients after trans-anal endoscopic microsurgery (TEM), who underwent endoscopic ultrasound surveillance instead of normal colonoscopy surveillance. These patients are referred to as "other" in Fig. 1.

In the first 6 months after resection, 240 patients underwent their first follow-up colonoscopy. One hundred and forty-three $(59.6 \%)$ of these patients were subjected to a completing colonoscopy. During these procedures, a total of five synchronous tumours $(3.5 \%)$ were detected (T1 stadium $N=3$, T3 stadium $N=2$ ). In the remaining 97 patients $(40.4 \%)$, colonoscopy was performed as a part of the surveillance programme, and four tumours $(4.1 \%)$ were detected, two of them were classified as $\mathrm{T} 1$ and the other two tumours as T2. One of these four tumours was an anastomotic recurrence, and the remaining three were primary tumours. In these first 6 months, there were nine patients $(3.6 \%)$ who did not participate in the colonoscopy surveillance programme but developed anastomotic recurrence $(N=1)$, local recurrence $(N=7)$, or a second primary tumour $(N=1)$. These tumours were diagnosed with positron emission tomography-computed tomography (PETCT) or computed tomography (CT). Most patients had their first follow-up colonoscopy between 6 and 18 months postoperatively $(n=1016,61.8 \%)$. Twenty-six patients underwent completing colonoscopy, which revealed no additional synchronous tumours. So in the first 18 months in 169 completing colonoscopies, five synchronous tumours were found $(3.0 \%)$. Thirty colorectal tumours were found with colonoscopy in the remaining 990 patients between the first 6 and 18 months (3.0\%). Twenty-four patients were diagnosed with recurrent disease without colonoscopy (2.3\%), 22 patients had local recurrence, one patient had anastomotic recurrence and one patient had a second primary tumour. The results for later time intervals regarding the first postoperative colonoscopy and their findings are given in Table 3. In total, at the first postoperative surveillance endoscopic follow-up, 50 tumours were found among 1475 patients who attended to the colonoscopy surveillance programme and 47 patients in which tumours were detected by other diagnostic imaging modalities (PET-CT, CT, or MRI) or perioperatively (during laparotomy), rather than by colonoscopy (2.9\%).

Including completing colonoscopies, in 1644 patients who underwent a first follow-up colonoscopy, 55 (3.3\%) colorectal tumours were found (Table 3; Fig. 1). The results for later time intervals regarding the second and third postoperative colonoscopy are given in Tables 4 and 5 in the Appendices. 


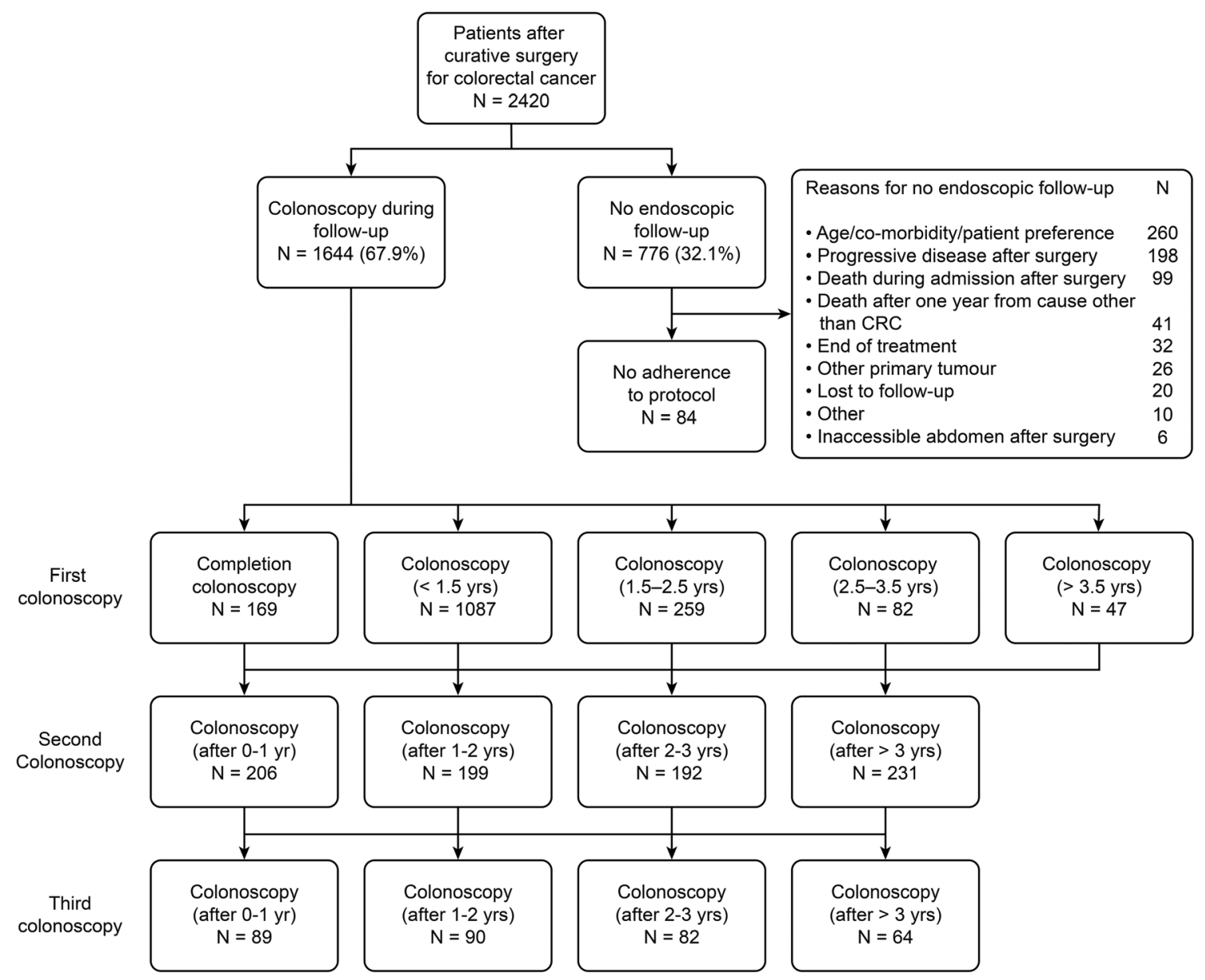

Fig. 1 Flowchart of 2420 patients attending follow-up after surgery for colorectal cancer

Iatrogenic perforation that required acute surgery was found in three $(0.14 \%)$ out of 2141 patients who underwent preoperative colonoscopy in this series. Two

Table 2 Overview of different type of resections that were performed arranged from right to left sided resections

\begin{tabular}{ll}
\hline Type of resection & Number of patients, $N=2420(\%)$ \\
\hline Ileocaecal resection & $36(1.5 \%)$ \\
Right hemicolectomy & $723(29.9 \%)$ \\
Transversal resection & $62(2.6 \%)$ \\
Left hemicolectomy & $167(6.9 \%)$ \\
(Recto)sigmoidal resection & $346(14.3 \%)$ \\
Anterior resection & $117(4.8 \%)$ \\
Hartmann procedure & $174(7.2 \%)$ \\
Low anterior resection & $495(20.4 \%)$ \\
Abdominal perineal resection & $230(9.5 \%)$ \\
Subtotal colectomy & $31(1.3 \%)$ \\
Transanal endoscopic microsurgery & $31(1.3 \%)$ \\
Total colectomy with pouch & $1(0.04 \%)$ \\
Total colectomy with ileostomy & $5(0.2 \%)$ \\
Abdominal polypectomy & $2(0.1 \%)$ \\
\hline
\end{tabular}

patients had a right hemicolectomy and one had a transversal resection. In the 2797 postoperative colonoscopies, iatrogenic perforation occurred in four patients, which was followed by emergency surgery $(0.14 \%)$. One patient underwent a sigmoid resection, one patient underwent a right hemicolectomy, and two patients had revision of their colostomy due to a perforation near the colostomy. One of these latter two patients had a complicated course after colonoscopy, with severe abdominal sepsis due to intraabdominal abscesses and underwent multiple laparotomies requiring prolonged stay at the intensive care unit. In one case, colonoscopy had to be postponed because of a significant decrease in oxygen levels to below $85 \%$ after sedation was administered.

\section{Discussion}

The aim of this study was to determine the incidence of CRC recurrence found by means of endoscopic surveillance after curative resection. We found an incidence of $3.1 \%$ between the first 6 and 18 months postoperative, which is similar to rates in some other cohorts [20-22], 
Table 3 Time intervals of patients receiving their first surveillance colonoscopy and tumour findings after curative resection

\begin{tabular}{|c|c|c|c|c|c|c|}
\hline Time interval & $\begin{array}{l}\text { Number } \\
\text { of patients }\end{array}$ & $\begin{array}{l}\text { Total number of } \\
\text { tumours found }\end{array}$ & $\begin{array}{l}\text { Anastomotic } \\
\text { recurrence }\end{array}$ & $\begin{array}{l}\text { Local } \\
\text { recurrence }\end{array}$ & $\begin{array}{l}\text { 2nd primary } \\
\text { tumour }\end{array}$ & Diagnostic imaging \\
\hline $0-6$ months & 249 & 18 & 2 & 7 & 9 & \\
\hline Completing & 143 & 5 & - & - & 5 & - \\
\hline Surveillance & 97 & 4 & 1 & - & 3 & - \\
\hline No colonoscopy & 9 & 9 & 1 & 7 & 1 & $2 \times$ PET $2 \times \mathrm{CT}$ \\
\hline $0.5-1.5$ year & 1040 & 54 & 16 & 24 & 14 & \\
\hline Completing & 26 & 0 & 0 & 0 & 0 & - \\
\hline Surveillance & 990 & 30 & 15 & 2 & 13 & - \\
\hline No colonoscopy & 24 & 24 & 1 & 22 & 1 & $12 \times \mathrm{CT} 9 \times$ PET $1 \times$ periop $2 \times \mathrm{MRI}$ \\
\hline $1.5-2.5$ year & 270 & 23 & 10 & 10 & 3 & \\
\hline Completing & - & - & - & - & - & - \\
\hline Surveillance & 259 & 12 & 8 & 1 & 3 & - \\
\hline No colonoscopy & 11 & 11 & 2 & 9 & - & $8 \times \mathrm{CT} 3 \times \mathrm{PET}$ \\
\hline 2.5-3.5 year & 83 & 5 & 1 & 2 & 2 & \\
\hline Completing & - & - & - & - & - & - \\
\hline Surveillance & 82 & 4 & 1 & 1 & 2 & - \\
\hline No colonoscopy & 1 & 1 & - & 1 & - & $1 \times$ Periop \\
\hline$>3.5$ year & 49 & 2 & 0 & 2 & 0 & \\
\hline Completing & - & - & - & - & - & - \\
\hline Surveillance & 47 & 0 & - & - & - & - \\
\hline No colonoscopy & 2 & 2 & - & 2 & - & 1x PET 1x CT \\
\hline
\end{tabular}

although higher incidence rates between $6.3 \%$ and $41 \%$ [23-27] and much lower incidence rates between 0.6 and $1.3 \%$ [28-30] have also been reported. A comparison of our results with the current literature is challenging for several reasons. First, there is no consensus definition of metachronous and synchronous tumours. In the literature, the time interval used to distinguish between these tumours ranges from 6 months to 3 years after curative surgery. In most reports, metachronous cases are defined as a second $\mathrm{CRC}$ at a site other than that of the anastomosis that appeared at least 6 months after primary surgery [31]. However, there are reports that use a different time interval (12 months [30]) or do not define the time interval [20,32]. Second, there is heterogeneity in the duration of follow-up among different reports, and there are differences among studies in the study population. Some cohorts are based on national CRC databases or patients from multicentre studies, whereas other studies only included patients operated on in a single centre, as with our cohort.

Ninety-seven patients had their first postoperative colonoscopy within 6 months, and four metachronous CRC cases were detected. Remarkably, preoperative colonoscopies in these patients were classified as complete. These tumours were labelled metachronous CRC but could alternatively be considered as synchronous because these lesions might have been undetected and therefore not removed during preoperative colonoscopy. If appropriate endoscopic removal of premalignant lesions is performed at the time of diagnosis of the primary tumour, any lesions found during following colonoscopies are categorized as metachronous [6]. However, it is possible that some of these synchronous lesions were missed during preoperative colonoscopy, meaning this index colonoscopy should be classified as incomplete. These colonoscopies could be of questionable quality due to poor intestinal preparation. Flat adenomas or depressed lesions have a fairly high malignant potential $[33,34]$. These adenomas are considered difficult to trace during diagnostic or surveillance colonoscopy, especially when the bowel is poorly prepared. Another potential explanation for the detection of metachronous $\mathrm{CRC}$ in these patients is that the development of CRC was accelerated and aggressive.

In this study, most of the patients received their first postoperative colonoscopy approximately 18 months after curative surgery; this is consistent with Cooper et al. [21]. However, a third of the patients had no surveillance; this might be explained by co-morbidity, age, or diseaserelated factors. Unfortunately, in 84 patients $(10.8 \%)$, surveillance was not fulfilled for unknown reasons. Seven of these patients $(8.3 \%)$ developed a second CRC with a median time interval of 30 months (range 3-60 months) after curative surgery. These tumours were all classified as local recurrence and were found with PET-CT or CT scan. The survival benefit to these patients likely would have 
improved if they had continued to attend at the colonoscopy surveillance programme.

Unfortunately, because of the retrospective nature of this study, no survival analyses could be made because of the high risk of selection bias, as physicians might have discouraged surveillance colonoscopy in patients for whom the potential benefit of surveillance was low. Such patients have more co-morbidities that other patients or have progressive disease, which increases the risk of death relative to that of healthier patients who did undergo surveillance colonoscopy. Moreover, the patients who were offered colonoscopy were significantly younger than the patients in the no-colonoscopy group. However, there are studies that found a survival benefit compared to patients who did not attend to an endoscopic follow-up programme [30, 35-37]. Three published randomized controlled trials (RCTs) involving intensive follow-up found no benefit compared to a normal surveillance programme $[26,27,38]$. Three systematic reviews found a higher 5year survival with a reduction of mortality of $9-13 \%$ in intensive follow-up group compared with the control group [39-41]. However, in these reviews, intensive follow-up involved all diagnostic modalities within the full follow-up schedule (imaging, CEA and colonoscopy) and do not consider the effects of colonoscopy alone. In one published RCT, comparison among surveillance schedules was performed, with other diagnostic modalities (CEA and imaging) held constant. This trial showed no better survival in patients who attended to an intensive follow-up schedule [42]. In this study, local recurrences were included, which do not necessarily grow intraluminally. Endoscopic surveillance alone would not be useful enough for patients with local recurrence; therefore, other imaging techniques should be part of a surveillance programme [43, 44]. In the first 18 months after curative surgery, we detected 33 tumours with imaging (PET-CT, CT and MRI) and one CRC perioperatively. This case concerns an 89-year-old male who presented with an ileus and underwent emergency surgery because of a pelvic tumour which was grown into the small intestines. After the total follow-up time, 77 tumours were found with other imaging modalities (Tables 3, 4 and 5).

In general, it is recommended to perform a preoperative diagnostic colonoscopy and a colonoscopy after curative surgery for CRC during follow-up. Unfortunately, colonoscopy entails some risk of complications, as well as patient discomfort during preparation and the procedure itself. Complications can be mild, such as a minor bleeding, which can be solved with clipping and/or local adrenaline injections, but they can also be severe, requiring emergency surgery. The incidence of iatrogenic perforation was $0.14 \%$ for both preoperative and surveillance colonoscopies. This is near the complication norm of the Dutch guidelines $(<0.1 \%)[8,45]$.

Early surveillance colonoscopy 1 year after curative surgery can be a cost-effective measure and thereby reduce medical costs $[46,47]$. However, to evaluate the optimal frequency and interval for surveillance colonoscopy, a prospective multicentre study should be performed to evaluate the results of colonoscopy after surgery. To evaluate and determine efficient surveillance colonoscopy intervals, current colonoscopy guidelines should be evaluated by an RCT in which patients, who undergo colonoscopy early after 3 or 6 months postoperatively, are compared with those undergoing normal surveillance colonoscopy after 1,3 and 5 years.

There are several biases in this retrospective observational cohort. Because of the retrospective design of this cohort, there was no randomization of patients. In addition, no distinction was made between colon and rectum among different age groups. Furthermore, no reliable distinction could be made between colonoscopies that were routine procedures in asymptomatic surveillance patients and those that were indicated based on developed symptoms or physical or laboratory findings. Additionally, the frequency and intervals of subsequent follow-up colonoscopy varied in our study population. Finally, it is globally accepted that most colorectal malignancies arise from adenomas and that screening or surveillance colonoscopy is recommended for the early detection of these adenomas or polyps. Such screening could lead to the detection of endoscopically curable stages of these lesions and avoid second operations. In this study, only malignant findings were analysed. Unfortunately, data regarding the numbers of detected advanced adenomas or polypectomies and their polyp characteristics including histology and size are not present in our database.

In conclusion, the results of this study indicate that it is relevant to perform colonoscopy for CRC to screen for anastomotic recurrence and metachronous tumours. We recommend a short-term surveillance colonoscopy approximately 1 year after curative surgery.

Compliance with Ethical Standards For ethical approval, we consulted the national institutional review board's Medical research Ethics Committees United (MEC-U). Referring to this study (reference number W17.073), confirmation was received that the Medical Research Involving Human Subject Act (WMO) does not apply; therefore, official approval of this study by the MEC-U was not required under the WMO. We also consulted the institutional review board of Amphia Hospital (AMOA), and they confirmed that no formal written waiver of ethics approval was required, because of the retrospective design of the study.

Conflict of Interest The authors declare that they have no conflict of interest. 


\section{Appendix}

Table 4 Time intervals of patients receiving their second colonoscopy surveillance with tumour findings after first follow-up colonoscopy

\begin{tabular}{|c|c|c|c|c|c|c|c|}
\hline Time interval & $\begin{array}{l}\text { Number of } \\
\text { patients }\end{array}$ & $\begin{array}{l}\text { 2nd recurrence } \\
\text { of CRC }\end{array}$ & $\begin{array}{l}\text { Total number } \\
\text { of tumours found }\end{array}$ & $\begin{array}{l}\text { Anastomotic } \\
\text { recurrence }\end{array}$ & $\begin{array}{l}\text { Local } \\
\text { recurrence }\end{array}$ & $\begin{array}{l}\text { 2nd primary } \\
\text { tumour }\end{array}$ & $\begin{array}{l}\text { Diagnostic } \\
\text { imaging }\end{array}$ \\
\hline $0-1$ year & 223 & 3 & 31 & 13 & 10 & 8 & \\
\hline Surveillance & 206 & 1 & 14 & 7 & - & 7 & - \\
\hline No colonoscopy & 17 & 2 & 17 & 6 & 10 & 1 & $\begin{array}{l}4 \times \text { periop } \\
10 \times \text { CT } 3 \times \text { PET }\end{array}$ \\
\hline $1-2$ year & 204 & 0 & 12 & 4 & 6 & 2 & \\
\hline Surveillance & 199 & - & 7 & 3 & 2 & 2 & - \\
\hline No colonoscopy & 5 & - & 5 & 1 & 4 & - & $1 \times \mathrm{CT} 4 \times \mathrm{PET}$ \\
\hline $2-3$ year & 193 & 1 & 8 & 4 & 0 & 4 & \\
\hline Surveillance & 192 & - & 7 & 3 & - & 4 & - \\
\hline No colonoscopy & 1 & 1 & 1 & 1 & - & - & $1 \times \mathrm{PET}$ \\
\hline$>3$ year & 233 & 1 & 5 & 1 & 2 & 2 & \\
\hline Surveillance & 231 & - & 3 & 1 & - & 2 & - \\
\hline No colonoscopy & 2 & 1 & 2 & - & 2 & - & $2 \times \mathrm{CT}$ \\
\hline
\end{tabular}

Table 5 Time intervals of patients receiving their third colonoscopy with tumour findings after follow-up colonoscopy

\begin{tabular}{|c|c|c|c|c|c|c|c|}
\hline Time interval & $\begin{array}{l}\text { Number } \\
\text { of patients }\end{array}$ & $\begin{array}{l}\text { 2nd recurrence } \\
\text { of CRC }\end{array}$ & $\begin{array}{l}\text { Total number } \\
\text { of tumours found }\end{array}$ & $\begin{array}{l}\text { Anastomotic } \\
\text { recurrence }\end{array}$ & $\begin{array}{l}\text { Local } \\
\text { recurrence }\end{array}$ & $\begin{array}{l}\text { 2nd primary } \\
\text { tumour }\end{array}$ & $\begin{array}{l}\text { Diagnostic } \\
\text { imaging }\end{array}$ \\
\hline $0-1$ year & 93 & 1 & 6 & 0 & 4 & 2 & \\
\hline Surveillance & 89 & 1 & 2 & - & - & 2 & \\
\hline No colonoscopy & 4 & - & 4 & - & 4 & - & $4 \times$ PET-CT \\
\hline $1-2$ year & 92 & 3 & 6 & 3 & 2 & 1 & \\
\hline Surveillance & 90 & 2 & 4 & 3 & & 1 & \\
\hline No colonoscopy & 2 & 1 & 2 & & 2 & & $1 \times$ PET CT $1 \times$ CT \\
\hline $2-3$ year & 82 & 1 & 2 & 0 & 0 & 2 & \\
\hline Surveillance & 82 & 1 & 2 & - & - & 2 & \\
\hline No colonoscopy & 0 & 0 & - & - & - & - & \\
\hline$>3$ year & 64 & 0 & 3 & 1 & 0 & 2 & \\
\hline Surveillance & 64 & - & 3 & 1 & - & 2 & \\
\hline No colonoscopy & 0 & - & - & - & - & - & \\
\hline
\end{tabular}

\section{References}

1. Bouvier AM, Latournerie M, Jooste V, Lepage C, Cottet V, Faivre J. The lifelong risk of metachronous colorectal cancer justifies long-term colonoscopic follow-up. Eur J Cancer. 2008;44:522-7.

2. Mulder SA, Kranse R, Damhuis RA, Ouwendijk RJ, Kuipers EJ, van Leerdam ME. The incidence and risk factors of metachronous colorectal cancer: an indication for follow-up. Dis Colon Rectum. 2012;55:522-31.

3. le Clercq C, Bouwens M, Riedl R, Beets GL, Winkens B, Hameeteman $\mathrm{W}$, et al. Incidence and potential causes for metachronous colorectal cancer: a 10-year retrospective survey. Gastroenterology. 2012;142:S-81.

4. Jayasekara H, Reece JC, Buchanan DD, Rosty C, Dashti SG, Ait Ouakrim D, et al. Risk factors for metachronous colorectal cancer following a primary colorectal cancer: a prospective cohort study. Int J Cancer. 2016;139:1081-90.

5. Parry S, Win AK, Parry B, Macrae FA, Gurrin LC, Church JM, et al. Metachronous colorectal cancer risk for mismatch repair gene mutation carriers: the advantage of more extensive colon surgery. Gut. 2011;60:950-7.

6. Rex DK, Kahi CJ, Levin B, Smith RA, Bond JH, Brooks D, et al. Guidelines for colonoscopy surveillance after cancer resection: a consensus update by the American Cancer Society and the US Multi-Society Task Force on Colorectal Cancer. Gastroenterology. 2006;130:1865-71.

7. Couch DG, Bullen N, Ward-Booth SE, Adams C. What interval between colorectal cancer resection and first surveillance colonoscopy? An audit of practice and yield. Color Dis. 2013;15:317-22.

8. Dutch Guidelines colonoscopy surveillance. Nederlandse Vereninging van Maag-, Darm en Leverartsen in samenwerking 
met Nederlandse Vereniging van Pathologie. https://www.mdl.nl/ sites/www.mdl.nl/files/richlijnen/Richtlijn_Coloscopie Surveillance_definitief_2013.pdf.

9. Engstrom, PF., Arnoletti, JP., Benson, AB $3^{\text {rd }}$., Chen, YJ., Choti, MA., Cooper HS et al. (2009), National Comprehensive Cancer Network. NCCN clinical practice guidelines in oncology: colon cancer. J Natl Compr Cancer Netw, 7: 778-831.

10. Cairns SR, Scholefield JH, Steele RJ, Dunlop MG, Thomas HJ, Evans GD, et al. Guidelines for colorectal cancer screening and surveillance in moderate and high risk groups (update from 2002). Gut. 2010;59:666-89.

11. Labianca, R., Nordlinger, B., Beretta, GD., Brouquet, A., Cervantes, A. (2010), ESMO Guidelines Working Group. Primary colon cancer: ESMO clinical practice guidelines for diagnosis, adjuvant treatment and follow-up. Ann Oncol, 21:70-77.

12. Poston, GJ., Tait, D., O'Connell, S., Bennett, A. and Berendse, S. (2011), Guideline Development Group. Diagnosis and management of colorectal cancer: summary of NICE guidance. BMJ, 343: d6751.

13. Khoury DA, Opelka FG, Beck DE, Hicks TC, Timmcke AE, Gathright JB. Colon surveillance after colorectal cancer surgery. Dis Colon Rectum. 1996;39:252-6.

14. Patchett SE, Mulcahy HE, O'Donoghue DP. Colonoscopic surveillance after curative resection for colorectal cancer. Br J Surg. 1993;80:1330-2.

15. Barrier A, Houry S, Huguier M. The appropriate use of colonoscopy in the curative management of colorectal cancer. Int J Color Dis. 1998;13:93-8.

16. Singh A, Kuo YF, Goodwin JS. Many patients who undergo surgery for colorectal cancer receive surveillance colonoscopies earlier than recommended by guidelines. Clin Gastroenterol Hepatol. 2013;11:65-72.

17. Cooper GS, Doug Kou T. Underuse of colorectal cancer screening in a cohort of Medicare beneficiaries. Cancer. 2008;112:293-9.

18. Jung WB, Yu CS, Lim SB, Park IJ, Yoon YS, Kim JC. Anastomotic recurrence after curative resection for colorectal cancer. World J Surg. 2017;41:285-94.

19. Landmann RG, Weiser MR. Surgical management of locally advanced and locally recurrent colon cancer. Clin Colon Rect Surg. 2005;18:182-9.

20. Bülow S, Svendsen LB, Mellemgaard A. Metachronous colorectal carcinoma. Br J Surg. 1990;77:502-5.

21. Cooper GS, Yuan Z, Chak A, Rimm AA. Patterns of endoscopic follow-up after surgery for nonmetastatic colorectal cancer. Gastrointest Endosc. 2000;52:33-8.

22. Lee SY, Kim BC, Han KS, Hong CW, Sohn DK, Park SC, et al. Incidence and risk factors of metachronous colorectal neoplasm after curative resection of colorectal cancer in Korean patients. $\mathrm{J}$ Dig Dis. 2014;15:367-76.

23. Barillari P, Ramacciato G, Manetti G, Bovino A, Sammartino P, Stipa V. Surveillance of colorectal cancer: effectiveness of early detection of intraluminal recurrences on prognosis and survival of patients treated for cure. Dis Colon Rectum. 1996;39:388-93.

24. Granqvist S, Karlsson T. Postoperative follow-up of patients with colorectal carcinoma by colonoscopy. Eur J Surg. 1992;158:307-12.

25. Cali RL, Pitsch RM, Thorson AG, Watson P, Tapia P, Blatchford GJ, et al. Cumulative incidence of metachronous colorectal cancer. Dis Colon Rectum. 1993;36:388-93.

26. Schoemaker D, Black R, Giles L, Toouli J. Yearly colonoscopy, liver CT, and chest radiography do not influence 5-year survival of colorectal cancer patients. Gastroenterology. 1998;114:7-14.
27. Mäkelä JT, Laitinen SO, Kairaluoma MI. Five-year follow-up after radical surgery for colorectal cancer. Results of a prospective randomized trial. Arch Surg. 1995;130:1062-7.

28. Cianchi F, Messerini L, Palomba A, Boddi V, Perigli G, Pucciani F, et al. Character of the invasive margin in colorectal cancer: does it improve prognostic information of Dukes staging? Dis Colon Rectum. 1997:40:1170-5.

29. Green RJ, Metlay JP, Propert K, Catalano PJ, Macdonald JS, Mayer RJ, et al. Surveillance for second primary colorectal cancer after adjuvant chemotherapy: an analysis of Intergroup 0089. Ann Intern Med. 2002;136:261-9.

30. Sakamoto T, Matsuda T, Nakajima T, Saito Y. How often should we perform surveillance colonoscopy after surgery for colorectal cancer? Int J Color Dis. 2013;28:835-40.

31. Moertel CG, Bargen JA, Dockerty MB. Multiple carcinomas of the large intestine: a review of the literature and a study of 261 cases. Gastroenterology. 1958;34:85-98.

32. Fukutomi Y, Moriwaki H, Nagase S, Tajika M, Naito T, Miwa Y, et al. Metachronous colon tumors: risk factors and rationale for the surveillance colonoscopy after initial polypectomy. J Cancer Res Clin Oncol. 2002;128:569-74.

33. Soetikno RM, Kaltenbach T, Rouse RV, Park W, Maheshwari A, Sato T, et al. Prevalence of nonpolypoid (flat and depressed) colorectal neoplasms in asymptomatic and symptomatic adults. JAMA. 2008;299:1027-35.

34. Matsuda T, Saito Y, Hotta K, Sano Y, Fujii T. Prevalence and clinicopathological features of nonpolypoid colorectal neoplasms: should we pay more attention to identifying flat and depressed lesions? Dig Endosc. 2010;22:57-62.

35. Winawer SJ, Zauber AG, Ho MN, O’Brien MJ, Gottlieb LS, Sternberg SS, et al. Prevention of colorectal cancer by colonoscopic polypectomy. The National Polyp Study Workgroup. N Engl J Med. 1993;329:1977-81.

36. Zauber AG, Winawer SJ, O'Brien MJ, Lansdorp-Vogelaar I, van Ballegooijen M, Hankey BF, et al. Colonoscopic polypectomy and long-term prevention of colorectal-cancer deaths. N Engl J Med. 2012;366:687-96.

37. Citarda, F., Tomaselli, G., Capocaccia, R., Barcherini, S, and Crespi, M. (2001), Italian Multicentre Study Group. Efficacy in standard clinical practice of colonoscopic polypectomy in reducing colorectal cancer incidence. Gut, 48: 812-815.

38. Kjeldsen BJ, Kronborg O, Fenger C, Jørgensen OD. A prospective randomized study of follow-up after radical surgery for colorectal cancer. Br J Surg. 1997;84:666-9.

39. Renehan AG, Egger M, Saunders MP, O’Dwyer ST. Impact on survival of intensive follow up after curative resection for colorectal cancer: systematic review and meta-analysis of randomised trials. BMJ. 2002;324:813.

40. Figueredo A, Rumble RB, Maroun J, Earle CC, Cummings B, McLeod R, et al. Follow-up of patients with curatively resected colorectal cancer: a practice guideline. BMC Cancer. 2003;3:26.

41. Jeffery M, Hickey BE, Hider PN. Follow-up strategies for patients treated for non-metastatic colorectal cancer. Cochrane Database Syst Rev. 2007;(1). https://doi.org/10. 1002/14651858.CD002200.pub2.

42. Wang T, Cui Y, Huang WS, Deng YH, Gong W, Li CJ, et al. The role of postoperative colonoscopic surveillance after radical surgery for colorectal cancer: a prospective, randomized clinical study. Gastrointest Endosc. 2009;69:609-15.

43. Barkin JS, Cohen ME, Flaxman M, Lindblad AS, Mayer RJ, Kalser $\mathrm{MH}$, et al. Value of a routine follow-up endoscopy program for the detection of recurrent colorectal carcinoma. Am J Gastroenterol. $1988 ; 83: 1355-60$ 
44. Kronborg O. Optimal follow-up in colorectal cancer patients: what tests and how often? Semin Surg Oncol. 1994;10:217-24.

45. BCSP Quality Assurance Endoscopy Group. Quality assurance guidelines for colonoscopy. NHS Cancer Screening Programmes 2011.

46. Hassan C, Pickhardt PJ, Zullo A, Di Giulio E, Laghi A, Kim DH, et al. Cost-effectiveness of early colonoscopy surveillance after cancer resection. Dig Liver Dis. 2009;41:881-5.
47. Lan YT, Lin JK, Li AF, Lin TC, Chen WS, Jiang JK, et al. Metachronous colorectal cancer: necessity of post-operative colonoscopic surveillance. Int J Color Dis. 2005;20:121-5.

Publisher's Note Springer Nature remains neutral with regard to jurisdictional claims in published maps and institutional affiliations. 